\title{
Correction to: Understanding the Buffering Effects of Protective Factors on the Relationship between Adverse Childhood Experiences and Teen Dating Violence Perpetration
}

Jordan P. Davis $\mathbb{D}^{1} \cdot$ Katie A. Ports ${ }^{2} \cdot$ Kathleen C. Basile ${ }^{2} \cdot$ Dorothy L. Espelage $^{3} \cdot$ Corinne F. David-Ferdon $^{2}$

Published online: 30 July 2019

(c) Springer Science+Business Media, LLC, part of Springer Nature 2019

\section{Correction to: Journal of Youth and Adolescence} https://doi.org/10.1007/s10964-019-01028-9

The article was initially published with incorrect copyright information. Upon publication of this Correction, the copyright of the article changes to "This is a U.S. Government work and not under copyright protection in the US; foreign copyright protection may apply."

The original article can be found online at https://doi.org/10.1007/ s10964-019-01028-9.

Jordan P. Davis

jordanpd@usc.edu

1 University of Southern California, Suzanne Dworak-Peck School of Social Work, Department of Children, Youth, and Families, USC Center for Artificial Intelligence in Society; USC Center for Mindfulness Science; USC Institute for Addiction Science, 669W 34th Street, Los Angeles, CA 90089, USA

2 Division of Violence Prevention, National Center for Injury Prevention and Control, Centers for Disease Control and Prevention, Buford, GA, USA

3 University of Florida, Gainesville, FL, USA 